\title{
Health ministers in west Africa hold crisis talks on Ebola virus
}

\author{
Anne Gulland \\ London
}

Health ministers from 11 countries in west Africa met in Ghana last week to discuss the response to what the World Health Organization has described as an "unprecedented" outbreak of the Ebola virus.

The ministers called for immediate action to help contain the outbreak, which has spread through three countries in west Africa since March this year. They said that, despite efforts to tackle the outbreak, a number of gaps and challenges remained in managing the disease: coordination, financing, communication, cross border collaboration, logistics, case management, infection control, surveillance, contact tracing, community participation, and research.

Ministers have pledged to mobilise community, religious, and political leaders to improve awareness and understanding of the disease and to strengthen surveillance, case finding, reporting, and contact tracing.

The recent outbreak began in the rural area of Gueckedou in Guinea but has since spread across the border into Sierra Leone and Liberia. As of 30 June, 759 cases had been recorded, including 467 deaths - although fewer than half of those had been confirmed. Guinea has seen the most cases, with 413 cases including 303 deaths, followed by Sierra Leone with 239 cases and 99 deaths, and Liberia with 107 cases and 65 deaths.

The disease was first reported in Zaire (now the Democratic Republic of Congo) along the Ebola River in 1976, and the biggest outbreak until this year was in Uganda in 2000-01, with 425 cases and 224 deaths

Speaking at the meeting of ministers, WHO's regional director for Africa, Luis Gomes Sambo, urged countries to "leave no stone unturned" in their response. He warned that the current outbreak had the potential to spread outside the affected countries and beyond the region "if urgent and relevant containing measures are not put in place."

He added that the continuing spread of the virus was "in great extent associated with some cultural practices and traditional beliefs which are contrary to recommended public health preventive measures." These include the practice of washing bodies before burial.

"In addition, the extensive movement of people within and across borders has facilitated rapid spread of the infection across and within the three countries," he added.

Médecins sans Frontières, the only non-governmental organisation working in the affected area, welcomed the ministerial meeting but said that urgent, concrete action was needed. Qualified and trained medical staff were in short supply, and action on contact tracing and raising awareness needed to be stepped up, said the aid agency.

"It is equally important to see a complete mobilisation of all leaders and people of influence in the affected countries to help diffuse public health messages to the affected communities," it said in a statement.

Much misinformation and fear about the disease has reportedly spread among local populations, and health staff have faced increasing levels of hostility from the local people, including accusations of trading body parts.

Speaking on the BBC World Service Bart Janssens, operations director of Médecins sans Frontières, said, "Quite a lot of the villages we cannot go into anymore to follow up on contacts with patients or even to evacuate patients to bring them into our treatment centres." Villagers were armed with bows, arrows, and spears in their attempts to stop health workers from coming in, he added.

In Sierra Leone and Monrovia, the Liberian capital, it is now a punishable offence to harbour an Ebola patient without informing the authorities.

Cite this as: BMJ 2014;349:94478

๑) BMJ Publishing Group Ltd 2014 